ARTICLE

DOI: $10.1038 / \mathrm{s} 41467-018-07159-0$

\title{
Electrochemically-mediated selective capture of heavy metal chromium and arsenic oxyanions from water
}

\author{
Xiao Su (1) ${ }^{1}$, Akihiro Kushima ${ }^{2,3}$, Cameron Halliday ${ }^{1}$, Jian Zhou $^{2}$, Ju Li (i) ${ }^{2} \&$ T. Alan Hatton (i) ${ }^{1}$
}

The removal of highly toxic, ultra-dilute contaminants of concern has been a primary challenge for clean water technologies. Chromium and arsenic are among the most prevalent heavy metal pollutants in urban and agricultural waters, with current separation processes having severe limitations due to lack of molecular selectivity. Here, we report redox-active metallopolymer electrodes for the selective electrochemical removal of chromium and arsenic. An uptake greater than $100 \mathrm{mg} \mathrm{Cr} / \mathrm{g}$ adsorbent can be achieved electrochemically, with a 99\% reversible working capacity, with the bound chromium ions released in the less harmful trivalent form. Furthermore, we study the metallopolymer response during electrochemical modulation by in situ transmission electron microscopy. The underlying mechanisms for molecular selectivity are investigated through electronic structure calculations, indicating a strong charge transfer to the heavy metal oxyanions. Finally, chromium and arsenic are remediated efficiently at concentrations as low as $100 \mathrm{ppb}$, in the presence of over 200-fold excess competing salts.

\footnotetext{
${ }^{1}$ Department of Chemical Engineering, MIT, 77 Massachusetts Avenue, Cambridge, MA 02139, USA. ${ }^{2}$ Department of Nuclear Engineering, MIT, 77 Massachusetts Avenue, Cambridge, MA 02139, USA. ${ }^{3}$ Present address: Department of Materials Science and Engineering, University of Central Florida, 12760 Pegasus Drive, Orlando, FL 32816, USA. Correspondence and requests for materials should be addressed to T.A.H. (email: tahatton@mit.edu)
} 
T he issues of anthropogenic water pollution and geographical scarcity of clean water on a global scale are some of the main engineering challenges of the twenty-first century $^{1}$. Heavy metal contaminants have been a major health and environmental hazard across the world. Chromium, in particular, is a priority target for the Environmental Protection Agency (EPA) due to its prevalence and high degree of toxicity ${ }^{2-4 ;}$ it is among the 10 most frequently detected ground water contaminants at hazardous waste sites, and one of the 14 most toxic heavy metals, especially when present in its hexavalent, oxyanion state (e.g., $\left.\mathrm{Cr}_{2} \mathrm{O}_{7}{ }^{2-}, \mathrm{CrO}_{4}{ }^{2-}, \mathrm{HCrO}_{4}{ }^{-}\right)^{5,6}$. Major sources of pollution include tanneries and metal plating, and are of concern both in the United States and the developing world. Whereas trivalent $\mathrm{Cr}(\mathrm{III})$ is a naturally occurring form in the earth's crust, hexavalent $\mathrm{Cr}(\mathrm{VI})$ is an anthropogenic chemi$\mathrm{Cal}^{7}$-as such, the development of energy-efficient pathways for capture of $\mathrm{Cr}(\mathrm{VI})$ and conversion to $\mathrm{Cr}(\mathrm{III})$ is key to long-term environmental sustainability ${ }^{2,6}$. Arsenic is another heavy metal in its highly soluble oxyanion form that has received strong interest both in North America and developing countries due to its acute health effects ${ }^{8,9}$, and wide prevalence from both natural and anthropogenic sources ${ }^{10}$. Conventional methods for heavy metal removal involve ion exchange or chemical resins for adsorption, which often require co-reagents or excessive regeneration chemicals ${ }^{11}$, and can suffer from slow kinetics with processing times on the order of hours ${ }^{12-14}$.

The development of smart materials for water purification and environmental remediation has received intense attention recently, with micropollutants and trace contaminants being key areas of concern ${ }^{15}$. Electrosorption-based processes often offer an attractive platform due to their modularity and the absence of a chemical regeneration step, based on a wide variety of material platforms for both deionization ${ }^{16-19}$ and selective ion removal $^{20-22}$. Redox-active materials have recently been demonstrated to be a promising platform for separations due to their molecular selectivity and electronic tunability ${ }^{23,24}$. Metallopolymer-based electrodes, especially poly(vinyl)ferrocene (PVF), have shown remarkable ion-uptake capacities for organic contaminants based on electrochemically activated chemical interactions $s^{23-25}$. The main features of these systems are the fast electron transfer and redox processes at moderate potentials $(<1.2 \mathrm{~V}$ vs. standard hydrogen electrode (SHE)), which allow reversible adsorption and desorption of ionic components by electrochemical modulation of charge and hydrogen-bonding interactions between carboxylates and the metallopolymers. A universal redox material platform, targeting the molecular level recognition of heavy metal oxyanions (HMOAs), would overcome a major challenge for environmental remediation, especially in the presence of competing excess anions. Furthermore, the nature of the interaction of these metallopolymers with relevant transition metals has not yet been fully explored.

In the current work, PVF-functionalized electrodes are applied in the removal of anionic chromium and arsenic oxyanions, under a range of different concentrations and electrolyte conditions. In addition, we provide insight into the transformation of chromium, which is reduced to its trivalent form during release on reduction of the metallopolymer adsorbent. From a general perspective, we demonstrate the high selectivity of Faradaic electrodes for HMOA contaminants, with the adsorption and desorption controlled purely by electrochemical modulation. The fundamental interactions regulating the selectivity are shown to depend strongly on solvation effects and on the charge transfer characteristics of the ion pair, regulated by the electronic structure of the anions and overcoming simple electrostatic attractions. In addition, we pursue the nanoscale observation of our metallopolymer film under ion adsorption using in situ electrochemical transmission electron microscopy (TEM). In situ TEM allows the direct high-resolution imaging and observation of an electrochemical response of a material interface, and can thus shed light on the kinetics and morphological changes during ion insertion in a direct manner. Our results are expected to serve as an important platform for tailoring advanced redox materials targeting heavy metal recovery and remediation.

\section{Results}

Electrosorption of chromium. The effectiveness of PVF as a heterogeneous, electrochemically mediated adsorbent for the removal of chromate from water was evaluated using uniform, nanostructured films of multiwalled carbon nanotubes (CNTs) and PVF prepared by a drop-casting method ${ }^{23,26}$. The nanoporous structure of the film was observed clearly by high-resolution scanning electron microscope (Fig. 1a), with the iron content confirmed by energy-dispersive spectroscopy (EDS). Chromium adsorption was carried out from a mixture of $1 \mathrm{mM}\left(\mathrm{NH}_{4}\right)_{2} \mathrm{Cr}_{2} \mathrm{O}_{7}$ and $20 \mathrm{mM} \mathrm{ClO}_{4}{ }^{-}$under chronoamperometric conditions at $+0.8 \mathrm{~V}$ vs. $\mathrm{Ag} / \mathrm{AgCl}$ (starting current $\sim 2 \mathrm{~mA} / \mathrm{cm}^{2}$ as seen in Supplementary Figure 8). After $2 \mathrm{~h}$ of adsorption, the increase in chromium on the PVF-CNT film was evident through EDS mapping (Fig. 1b). X-ray photoelectron spectroscopy (XPS) surface analysis also confirmed the high uptake of chromium relative to the CNT control, in which no visible chromium adsorption was observed (Supplementary Figures 13 and 14). At $10 \mathrm{mM} \mathrm{Cr}_{2} \mathrm{O}_{7}{ }^{2-}$ and $20 \mathrm{mM} \mathrm{ClO}_{4}^{-}$(equimolar chromium and perchlorate concentrations in the mixture), a molar comparison found a close to stoichiometric ratio between chromium and iron, indicating the strong chromate-ferrocenium binding as an ion pair (Fe2p 1.25:1 $\mathrm{Cr} 2 \mathrm{p}$ ratio, $\mathrm{Cl}<0.1 \%$, from high-resolution XPS quantitation). With chromate as the minority ion $\left(1 \mathrm{mM} \mathrm{Cr}_{2} \mathrm{O}_{7}{ }^{2-}\right.$ and $20 \mathrm{mM}$ $\left.\mathrm{ClO}_{4}^{-}\right)$, the degree of competing perchlorate adsorption increased (Cr2p 1.3:1 Cl2p ratio), with the iron to chromium ratio approaching 4:1 (from both survey and high-resolution scans), which approximately correlates with the experimental adsorption capacity of $\sim 60 \mathrm{mg} / \mathrm{g}$ (Fig. 1c). A total elemental analysis from the survey scans also points to a certain degree of cation $\left(\mathrm{Na}^{+}\right.$and $\mathrm{NH}_{4}{ }^{+}$) insertion within the film (Supplementary Figure 13) due to charge compensation to ensure electroneutrality.

On varying the potential applied to the PVF-CNT electrode, we noticed that chromium adsorption was the highest under full oxidation of PVF (at $+0.8 \mathrm{~V}$ vs. $\mathrm{Ag} / \mathrm{AgCl}$ ), with little to no adsorption below $+0.4 \mathrm{~V}$ (Fig. 1c), with either perchlorate or chloride as the supporting electrolyte. Under higher potentials, more ferrocene $(\mathrm{Fc})$ units in the electrode become oxidized to allow for chromate binding. As will be discussed later, these observations are also in agreement with the results from in situ TEM, which showed polymer expansion at the peak redox potential of the cyclic voltammetry (CV) (see Supplementary Movies 1-5). An equilibrium isotherm at $+0.8 \mathrm{~V}$ vs. $\mathrm{Ag} / \mathrm{AgCl}$ shows that a maximum capacity of up to $100 \mathrm{mg}$ chromium/g adsorbent can be achieved in perchlorate (Fig. 1d), which is higher than loadings reported for various ion-exchange materials and nanoparticle sorbents ${ }^{14,27}$; the advantage of our redox electrodes is that they are fully electrochemically controlled and do not require the addition of chemical regenerants to release the captured ions, with remarkably higher selectivity and adsorption uptake than conventional carbon electrodes ${ }^{28}$. In addition, the adsorption reaches fast equilibrium across a range of concentrations (Fig. 1e and Supplementary Figure 10), which is remarkable in comparison to various ion-exchange or other electrosorption systems, which often require hours to reach adsorption equilibrium ${ }^{12-14}$. These fast adsorption rates are comparable to capacitive methods in deionization ${ }^{16-19}$, with the added advantage of the high 
a

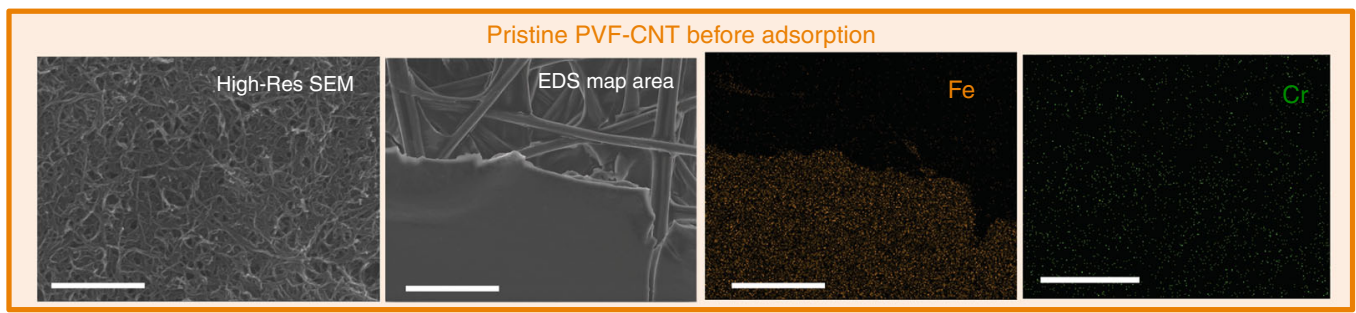

b

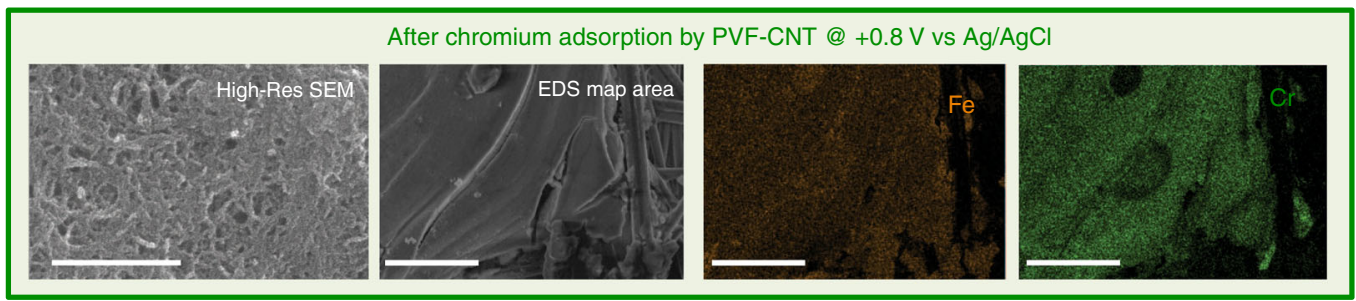

C
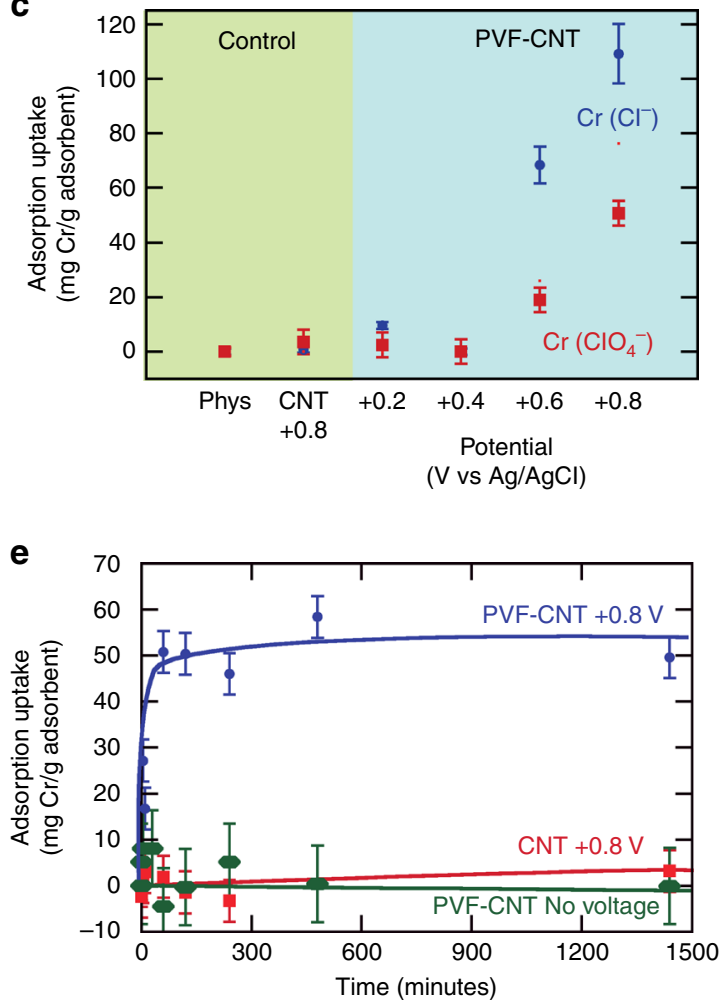

d

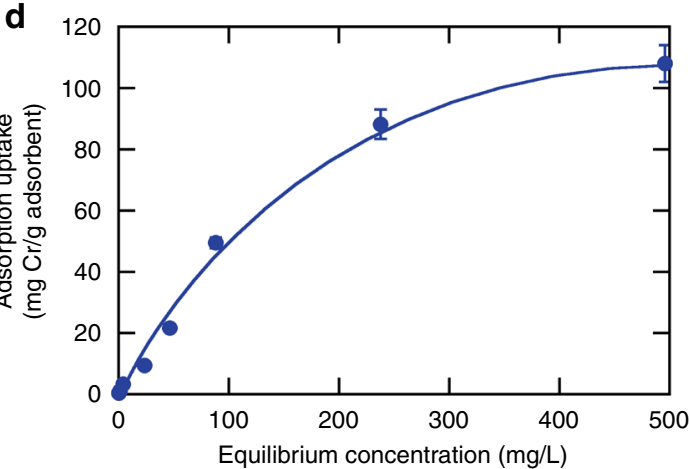

f

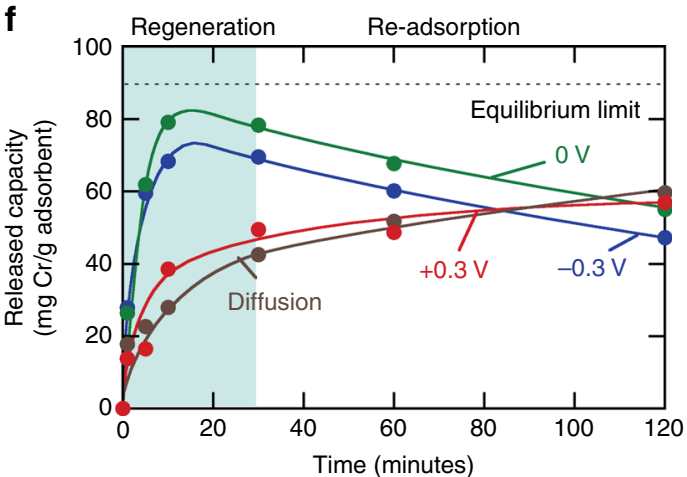

Fig. 1 Electrosorption of chromium oxyanions by PVF-CNT. a Scanning electron microscopy (SEM) images of the PVF-CNT electrodes before the adsorption of chromium, and EDS mapping of the iron of the metallopolymer, and of adsorbed $\mathrm{Cr}$. $\mathbf{b}$ SEM micrographs and EDS mapping after chromium adsorption. The area corresponding to the PVF is also saturated with the adsorbed $\mathrm{Cr}$. c Comparison of chromium-uptake capacity of PVF-CNT and CNT electrodes, for $1 \mathrm{mM}(\mathrm{NH})_{4} \mathrm{Cr}_{2} \mathrm{O}_{7}$ in $20 \mathrm{mM} \mathrm{NaClO}_{4}$ and in $20 \mathrm{mM} \mathrm{NaCl}$. No Cr adsorption occurs on a PVF-CNT electrode without potential, and a much higher adsorption capacity for PVF-CNT than pristine CNT is observed at $+0.8 \mathrm{~V}$ vs. $\mathrm{Ag} / \mathrm{AgCl}$ potential adsorption. $\mathbf{d}$ Equilibrium isotherm for PVF-CNT at $+0.8 \mathrm{~V}$ vs. $\mathrm{Ag} / \mathrm{AgCl}$ adsorption for a range of $(\mathrm{NH})_{4} \mathrm{Cr}_{2} \mathrm{O}_{7}$ concentrations in $20 \mathrm{mM} \mathrm{NaClO}$. e Adsorption kinetics for $\mathrm{Cr}$ at $1 \mathrm{mM}(\mathrm{NH})_{4} \mathrm{Cr}_{2} \mathrm{O}_{7}$ in $20 \mathrm{mM}$ $\mathrm{NaClO}_{4}$. $\mathbf{f}$ Effect of discharge potential on regeneration efficiency of the PVF-CNT electrodes, measured by the normalized mass of $\mathrm{Cr}$ released (mg $\mathrm{Cr} / \mathrm{g}$ PVF polymer). Electrodes were charged at $+0.8 \mathrm{~V}$ (vs. $\mathrm{Ag} / \mathrm{AgCl}$ ) and discharged at $0,-0.3$, and $+0.3 \mathrm{~V}$ into $20 \mathrm{mM} \mathrm{NaClO}_{4}$, and dynamic results were compared to a diffusion-controlled case in which the electrode was left in the desorption solution under no applied potential. Scale bar for high-resolution SEM is $800 \mathrm{~nm}$, and scale bar for EDS and $\mathrm{Fe} / \mathrm{Cr}$ mapping is $50 \mu \mathrm{m}$. Error bars represent standard deviations from three replicate measurements

selectivity towards the select chromium anions in competition with interfering chloride ions. Neither a control CNT electrode (pristine $\mathrm{CNT}$ at $+0.8 \mathrm{~V}$ vs. $\mathrm{Ag} / \mathrm{AgCl}$ ) nor the neutral PVF-CNT (no voltage applied) exhibited affinity for the dichromate over the competing electrolyte (Fig. 1c, e). Finally, it must be noted that comparable chromium uptakes can be obtained by applying chronopotentiometric charging (at current densities varying from 0.1 to $1 \mathrm{~mA} / \mathrm{cm}^{2}$ ) and also with capacitive counter electrodes made of porous carbons (see Supplementary Figure 11).

Regeneration and spectroscopic analysis. Regeneration of the redox electrodes was accomplished through application of a lower 
potential to reduce $\mathrm{Fc}^{+}$and release the adsorbed chromium. A series of release conditions were tested including $-0.3,0$, and $+0.3 \mathrm{~V}$ and no applied potential (results shown in Fig. 1f). The release of up to $87 \%$ of the adsorbed chromium was achieved at 0 $\mathrm{V}$ vs. $\mathrm{Ag} / \mathrm{AgCl}$. A cycling study was carried out with the electrode charged at $+0.8 \mathrm{~V}$ vs. $\mathrm{Ag} / \mathrm{AgCl}$, in the presence of $1 \mathrm{mM}$ chromate for $10 \mathrm{~min}$, and discharged at $0 \mathrm{~V}$ vs. $\mathrm{Ag} / \mathrm{AgCl}$ into a clean electrolyte solution for $30 \mathrm{~min}$, which was then assayed for released chromium. Figure 2a shows that the working capacity of the electrode was retained at close to $55 \mathrm{mg} \mathrm{Cr} / \mathrm{g}$ adsorbent for a number of cycles with $100 \%$ regeneration efficiency per step starting at cycle 2 . In addition, no metallopolymer leaching was observed in a inductively coupled plasma (ICP) assay for Fe in the liquid phase, or from an XPS analysis of the PVF surface (equivalent iron \% before and after).

An illustrative scheme showing the full adsorption and release cycle is shown in Fig. 2c. A closer look at the voltage on the E-pH (aka Pourbaix) diagram can shed light on the pathways for chromium transformation during this electrochemical process (Fig. 2b). The $\mathrm{pH}$ of the adsorption mixture was initially $\sim \mathrm{pH}=$ 5 , and slowly increased during adsorption due to both water and oxygen reduction at the counter electrode (Supplementary Figure 16, Supplementary Figure 17, and Supplementary Figure 18). During discharge, the $\mathrm{pH}$ sharply dropped to $\sim 3.2-3.5$ due to water oxidation at the counter electrode. During the adsorption step, an electrochemical potential above $+0.8 \mathrm{~V}$ vs. $\mathrm{Ag} / \mathrm{AgCl}$, or $1.0 \mathrm{~V}$ vs. SHE, was applied, a range over which the anionic chromium dominates $\left(\mathrm{CrO}_{4}{ }^{2-}, \mathrm{HCrO}_{4}{ }^{-}\right.$, or $\mathrm{Cr}_{2} \mathrm{O}_{7}{ }^{2-}$, depending on the $\mathrm{pH}$ and total chromium concentration). Over the range of concentrations tested $(0.1-10 \mathrm{mM})$ and at $\mathrm{pH}=5$, $\mathrm{HCrO}_{4}{ }^{-}$is the predominant species prior to adsorption. As shown by XPS, in situ TEM, and the various adsorption tests, there is a strong selectivity of PVF for the chromate species over other competing anions during electrosorption following oxidation of the PVF-CNT electrode. To promote discharge of the captured ions, a lower reduction potential was applied $(0 \mathrm{~V}$ vs. $\mathrm{Ag} / \mathrm{AgCl},+0.2 \mathrm{~V}$ vs. $\mathrm{SHE})$, which brought the system down to a region in which cationic forms of chromium predominate (e.g., $\mathrm{Cr}(\mathrm{OH})_{3-x^{x+}}$. A negative potential $(-0.3 \mathrm{~V}$ vs. $\mathrm{Ag} / \mathrm{AgCl})$, even though it promoted a rapid desorption of the chromium from the Fc film, resulted in chromium re-adsorption onto the negatively polarized electrode after a certain period of time, probably due to the cationic predominance of $\mathrm{Cr}^{3+}$ and $\mathrm{Cr}(\mathrm{OH})_{2}{ }^{+}$. On the other hand, the $+0.3 \mathrm{~V}$ run showed a discharge profile comparable to that of the diffusion-controlled release of chromium (Fig. 1f), pointing to a slower reduction of the $\mathrm{Fc}$ units and subsequent release of chromium. The higher release at an applied potential of $0 \mathrm{~V}$ implies an optimal tradeoff between reduction of the metallopolymer and re-adsorption of any cationic chromium.

The spontaneous conversion of $\mathrm{Cr}(\mathrm{VI})$ to $\mathrm{Cr}(\mathrm{III})$ at the surface of the electrodes was corroborated by the XPS observation of a significant accumulation of $\mathrm{Cr}(\mathrm{OH})_{3-x^{x+}}$ on the electrode, based on the binding energy shift ( $\mathrm{Cr} 2 \mathrm{p}_{1 / 2}$ at $587.2 \mathrm{eV}$ and $\mathrm{Cr} 2 \mathrm{p}_{3 / 2}$ at $577.7 \mathrm{eV})^{29}$, as well as the $\mathrm{Cr}(\mathrm{VI})$ shoulder at $580 \mathrm{eV}$ (Supplementary Figure 14). The XPS profile supports the supposition of a surface-induced conversion of $\mathrm{Cr}(\mathrm{VI})$ to $\mathrm{Cr}(\mathrm{III})^{29}$. Chromate reduction by free ferrous iron $(\mathrm{Fe}(\mathrm{II}))$, in which water acts as a co-reagent, has been reported for natural aquatic systems ${ }^{30}$. Our method couples an electrochemical reduction step following removal of the chromate ions from the feed solution during the oxidation step. A liquid-phase spectrophotometric assay to evaluate the degree of $\mathrm{Cr}(\mathrm{VI})$ conversion to $\mathrm{Cr}(\mathrm{III})$ in the aqueous phase before and after reduction showed that both the stock solution (containing $1 \mathrm{mM} \mathrm{NH}_{4} \mathrm{Cr}_{2} \mathrm{O}_{7}$ ) and the supernatant after adsorption contained $\mathrm{Cr}(\mathrm{VI})$ as the majority species $(>98 \%)$. The preservation of the hexavalent form of chromium even after a

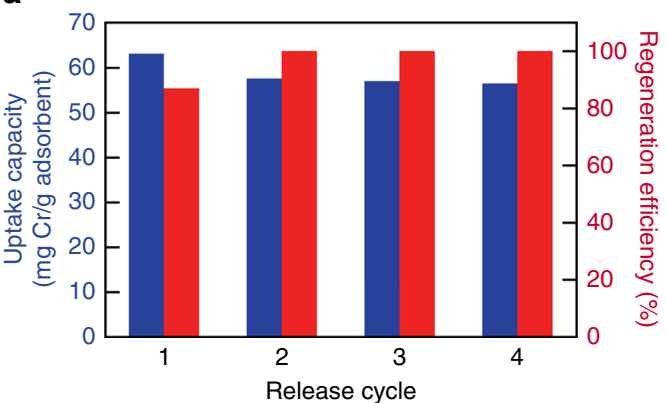

b

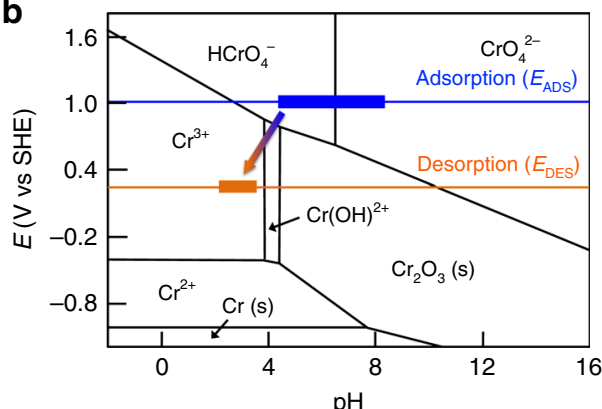

C
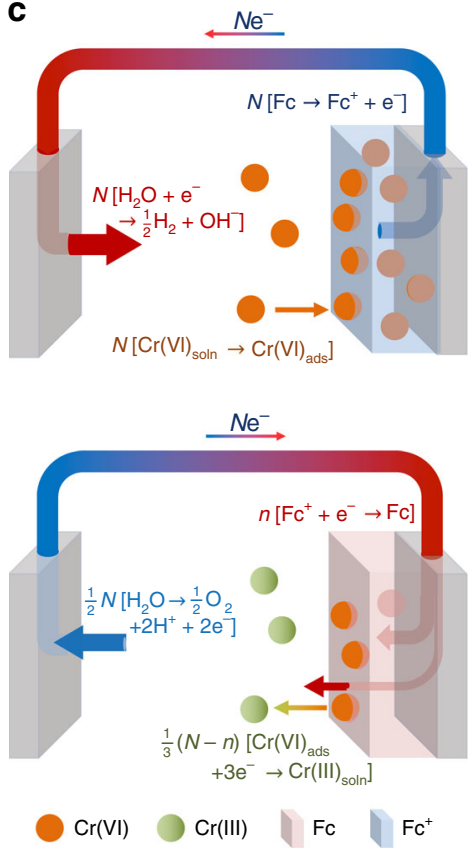

Fig. 2 Investigation of the reversibility of the electrochemically mediated capture-and-release process. a Recyclability of the electrode over a number of discharge cycles ( $+0.8 \mathrm{~V}$ adsorption, $0 \mathrm{~V}$ discharge), as given by the normalized mass released (in blue), and the regeneration efficiency (\%) (in red), the latter denoting the relative amount of $\mathrm{Cr}$ recovered relative to that adsorbed in each cycle. $\mathbf{b}$ The $E$-pH diagram for chromium speciation predominance, constructed with commercial thermochemical software (FactSage) at $25^{\circ} \mathrm{C}$ for $1 \mathrm{mM}$ total chromium concentration in the liquid phase. The adsorption and desorption potentials are noted, with the range of solution conditions marked both for adsorption (in blue) and desorption (in orange). c The Faradaic reactions occurring at the surface of the electrode pair are shown during both adsorption and release. During adsorption, hexavalent chromate is captured by the anode through selective binding, whereas during release, reduction of ferrocenium to ferrocene and of $\mathrm{Cr}(\mathrm{VI})$ to $\mathrm{Cr}(\mathrm{III})$ occurs 
electrochemical treatment under oxidation indicated that application of $+0.8 \mathrm{~V}$ vs. $\mathrm{Ag} / \mathrm{AgCl}$ does not change the oxidation state of bound $\mathrm{Cr}(\mathrm{VI})$. Also, the neutral Fc polymer showed no molecular affinity for the anions, as both XPS and spectrophometric assays indicated no conversion of $\mathrm{Cr}(\mathrm{VI})$ to $\mathrm{Cr}(\mathrm{III})$. However, after discharge at $0 \mathrm{~V}$ vs. $\mathrm{Ag} / \mathrm{AgCl}, 81 \%$ of the released chromium was found to be in the trivalent state of $\mathrm{Cr}$ (III), providing strong evidence that the electrochemically mediated release step promotes the transformation.

Here, we must note the importance of the anode in enabling the synergistic reduction of the chromium oxyanion at the cathode during the release process (Fig. 2c). Not only does water oxidation at the anode provide the electrons for reduction of both $\mathrm{PVF}^{+}$and $\mathrm{Cr}(\mathrm{VI})$, but the protons produced are crucial in that they regulate the $\mathrm{pH}$ towards a range in which the cationic species are soluble (see the $E-\mathrm{pH}$ diagram in Fig. $2 \mathrm{~b}$ ), and, conveniently, act as co-reagents in the reduction of $\mathrm{Cr}(\mathrm{VI})$ to $\mathrm{Cr}$ (III) species $^{30,31}$. A charge balance on the electrochemical system for electrons transferred to the cathode for $\mathrm{Cr}(\mathrm{VI})$ and $\mathrm{PVF}^{+}$ reduction, and from the anode, with the production of protons, gives a cathode current efficiency of around $100 \%$; the calculated value of $\sim 1.27$ Coulomb transferred to the cathode, based on the assumption of full $\mathrm{Fc}$ reduction coupled with the equivalent $\mathrm{Cr}$ (VI) transformation, agreed well with the experimentally determined value of 1.24 Coulomb of charge transferred during regeneration (Supplementary Figure 9). The balance of protons (based on $\mathrm{pH}$ change and estimated consumption during dichromate conversion) gives a theoretical anodic charge that also matches the cathodic charge. Thus, contrary to some other applications in which Faradaic solvent reactions are detrimental to selective separations and should be suppressed ${ }^{24}$, it is shown here that for cathodic regeneration of PVF, water oxidation aids in the regulation of the solvent $\mathrm{pH}$ in favor of the equilibrium
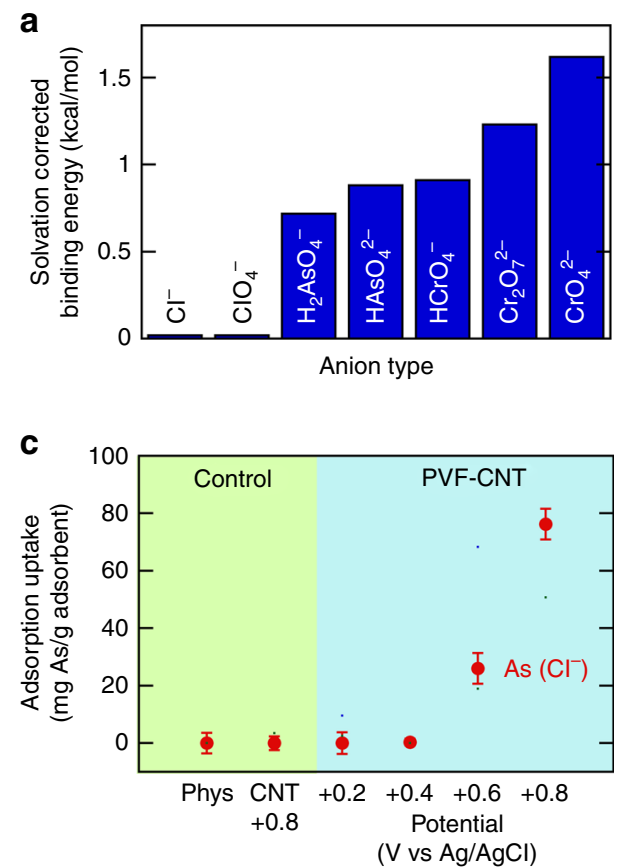

d

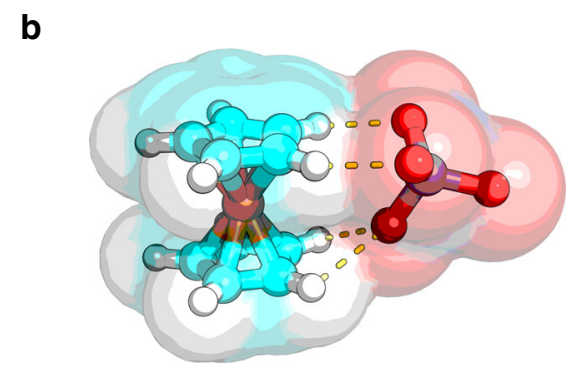

Mechanisms for selectivity towards HMOAs. Finally, the selectivity of the electrosorption step for HMOAs (chromium and arsenic) over chloride and perchlorate was investigated by density functional theory (DFT) calculations that allowed for water solvation effects. In Fig. 3a, we show the calculated binding energies between ferrocenium and a range of chromium and arseniccontaining oxyanions $\left(\mathrm{Cl}^{-}, \mathrm{ClO}_{4}^{-}, \mathrm{HCrO}_{4}^{-}, \mathrm{CrO}_{4}{ }^{2-}, \mathrm{Cr}_{2} \mathrm{O}_{7}{ }^{2-}\right.$, $\mathrm{H}_{2} \mathrm{AsO}_{4}{ }^{-}$, and $\mathrm{HAsO}_{4}{ }^{2-}$ ). In contrast with previous DFT calculations for $\mathrm{Fc}$ under gas-phase conditions ${ }^{23}$, we explore here the strong screening effect of solvation for chloride or perchlorate, and the strong selectivity towards electron-rich HMOAs. The overall binding energy values in the present work are more accurate as these plane-wave-based calculations do not need to account for basis-set superposition errors under solvation ${ }^{23}$. For instance, the bindings between $\mathrm{Fc}^{+}$and $\mathrm{CrO}_{4}{ }^{2-}, \mathrm{Cr}_{2} \mathrm{O}_{7}{ }^{2-}$, and $\mathrm{HAsO}_{4}{ }^{2-}$ are calculated to be $1.62,1.22$, and $0.91 \mathrm{kcal} / \mathrm{mol}$, respectively, but only 0.018 and $0.015 \mathrm{kcal} / \mathrm{mol}$ for $\mathrm{Cl}^{-}$and $\mathrm{ClO}_{4}^{-}$, even though the geometry optimizations are similar for perchlorates, arsenates, and chromates (Fig. 3b). The complete geometry optimizations are shown in Supplementary Figure 19 and Supplementary Table 2. These results strongly imply an underlying electronic effect. The average $\mathrm{O}-\mathrm{H}$ distance $(\mathrm{Cl}-\mathrm{H}$ for $\mathrm{Fc}-\mathrm{Cl})$ for these structures also corresponds to the shorter $d_{\mathrm{O}-\mathrm{H}}$ for cases with stronger binding (Supplementary Table 1).

A Bader's charge analysis ${ }^{32}$ showed that a significant fraction of electrons were transferred from the HMOAs to the oxidized Fc centers (Supplementary Table 1). The strong binding of $\mathrm{Fc}^{+}$with $\mathrm{CrO}_{4}{ }^{2-}$ and $\mathrm{HAsO}_{4}{ }^{2-}$ corresponded to more electron loss from the anions $(0.30$, and $0.41|e|)$, indicating that charge transfer

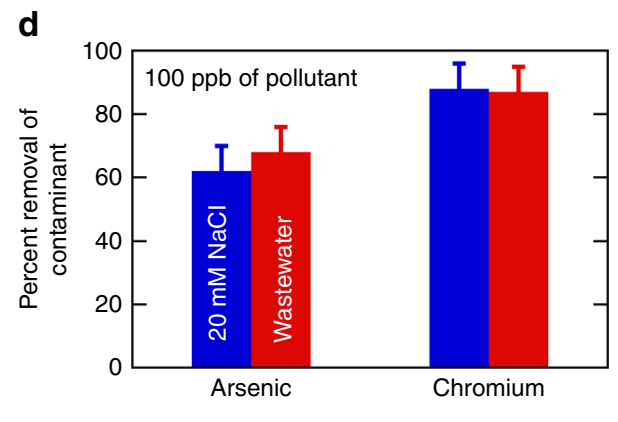

Fig. 3 Mechanistic study of binding selectivity and generalization to arsenic contaminants. a Comparison of zero-temperature, solvation corrected binding energies calculated by DFT between ferrocenium and a range of oxyanions. The binding energy for chromium and arsenic-based anions is remarkably stronger than for the purely electrostatic attraction of chloride and perchlorate. $\mathbf{b}$ Electronic structure optimization of chromate ( $\mathrm{CrO}{ }_{4}{ }^{2-}$ ) with ferrocenium $\left(\mathrm{FC}^{+}\right)$, indicating that despite similar structural effects to perchlorate binding, the main governing contribution to selectivity is derived from charge transfer. c Adsorption capacity of arsenate at $1 \mathrm{mM} \mathrm{KH}_{2} \mathrm{AsO}_{4}$ in the presence of $20 \mathrm{mM} \mathrm{NaCl}$, using PVF-CNT under different applied potentials. d Removal efficiency of chromium and arsenic under different water matrices, including a municipal secondary effluent solution spiked with $\mathrm{Cr}$ and As at 100 ppb for 120 min of charging (4 mg PVF on the electrode). Error bars represent standard deviations from three replicate measurements 
plays a dominant role in regulating binding selectivity. An atomby-atom analysis of the electron transfer showed that the oxygens on the HMOAs are much more susceptible to losing electrons to ferrocenium than those from the non-HMOAs, for example, $\mathrm{Cl}^{-}$ or $\mathrm{ClO}_{4}^{-}$, due to significant differences in their intrinsic electronegativities, as the $\mathrm{ClO}_{4}^{-}$(containing only halide and oxygen) is clearly more electronegative than $\mathrm{CrO}_{4}{ }^{2-}$ (containing a heavy metal center); thus, the electron cloud of $\mathrm{ClO}_{4}{ }^{-}$is much less polarizable than that of $\mathrm{CrO}_{4}{ }^{2-}$, and much less attracted to $\mathrm{Fc}^{+}$. This electron cloud polarizability/charge transfer can be quantified in terms of the ionization potential of the solvated anions, $\mathrm{IP}=E_{\mathrm{A}}{ }^{0 /-}-E_{\mathrm{A}}{ }^{-/ 2-}$, which can be interpreted as the energy required to remove one electron. A higher IP value indicates a higher barrier for electron transfer, roughly correlating with a weak $\mathrm{Fc}^{+}$binding. Clearly, under water solvation, the calculated IP values of $\mathrm{Cl}^{-}$and $\mathrm{ClO}_{4}^{-}(>7.2 \mathrm{eV})$ are higher than those of the chromates and arsenates studied here. Furthermore, the IP values for $\mathrm{CrO}_{4}{ }^{2-}$ and $\mathrm{HAsO}_{4}{ }^{2-}$ are smaller than those for all other anions (5.6 and $5.2 \mathrm{eV}$ ), consistent with the higher charge transfer and stronger binding.

While qualitatively powerful, zero-temperature calculations cannot be compared directly with experimental binding energies. We performed entropy-corrected binding calculations to investigate the effect of finite temperatures on the intermolecular interactions and thereby provide more meaningful values for the binding energies. Owing to the heavy computational costs for the optimization of the structures for this task (see details in Methods), we selected $\mathrm{Cl}^{-}, \mathrm{ClO}_{4}{ }^{-}, \mathrm{CrO}_{4}{ }^{2-}$, and $\mathrm{HAsO}_{4}{ }^{2-}$ as validation cases to explore the importance of vibrational entropy in determining molecular selectivity. The binding energies of these four compounds with ferrocenium, accounting for both solvation and entropy corrections, are $2.90,3.47,5.53$, and 4.73 $\mathrm{kcal} / \mathrm{mol}$, respectively. On comparison of these data with zerotemperature binding energies $(0.02,0.02,1.62$, and $0.91 \mathrm{kcal} / \mathrm{mol}$, respectively), it is evident that vibrational entropy contributes greatly to the selectivity of the binding events. In addition, the overall trend in the interaction energies predicted by the zero- temperature calculations is preserved. These results further strengthen our mechanistic understanding of the electronic nature of the interactions, and of the strong charge transfermediated discrimination between these compounds. These guidelines are expected to provide important future design rules for HMOA capture, and establish redox electrodes as electrochemically efficient and molecularly tunable platforms for chemical and environmental separations.

Separation of arsenate indeed showed a significant selectivity and adsorption uptake in competition with chloride at $1 \mathrm{mM}$ $\mathrm{AsO}_{4}{ }^{-}, 20 \mathrm{mM} \mathrm{NaCl}$ (Fig. 3c), in agreement with theoretical calculations. XPS analysis indicated that arsenic, under $+0.8 \mathrm{~V}$ adsorption and $+0 \mathrm{~V}$ release remained in the pentavalent arsenate state (Supplementary Figure 15), while also confirming the strong selectivity over chloride by the surface elemental partitioning. The release experiments showed reversible performance equivalent to that of chromium (Supplementary Figure 12), with a desorption trend that supports the anionic bound state (higher release at more negative potentials). Finally, the removal efficiency for chromium and arsenic at $100 \mathrm{ppb}$ was tested in the presence of a brackish concentration of sodium chloride $(20 \mathrm{mM} \mathrm{NaCl})$ and secondary effluent wastewater collected from the Deer Island Wastewater treatment plant (with a conductivity comparable to an ionic strength of $\sim 20-30 \mathrm{mM}$ ). It was observed that $>80 \%$ removal was achieved within $2 \mathrm{~h}$ of electrochemical adsorption (Fig. 3d), limited only by the capacity of the electrode.

In situ electrochemical TEM studies. Finally, the nanoscale behavior of our metallopolymer under electrical stimulus was studied through in situ TEM measurements in a liquid-confined cell (Fig. 4a, b). In situ electrochemical TEM has been introduced as a tool to study the kinetics and surface behavior of a variety of electrochemical materials and processes, ranging from lithiumion batteries to electrodeposition ${ }^{33-35}$. From a fundamental perspective, investigations on the nanoscale behavior of metallopolymers under electrochemical control are of great importance for
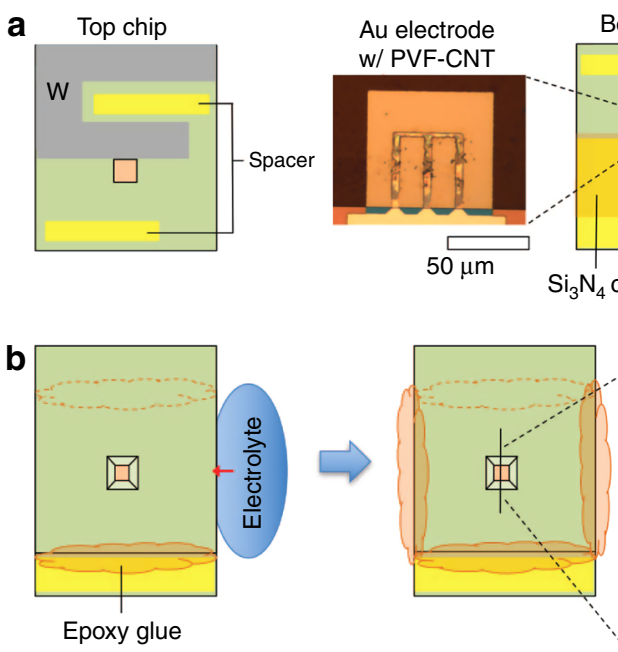
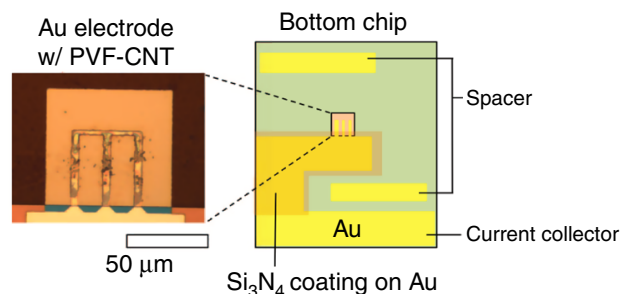

$\mathrm{Si}_{3} \mathrm{~N}_{4}$ coating on $\mathrm{Au}$
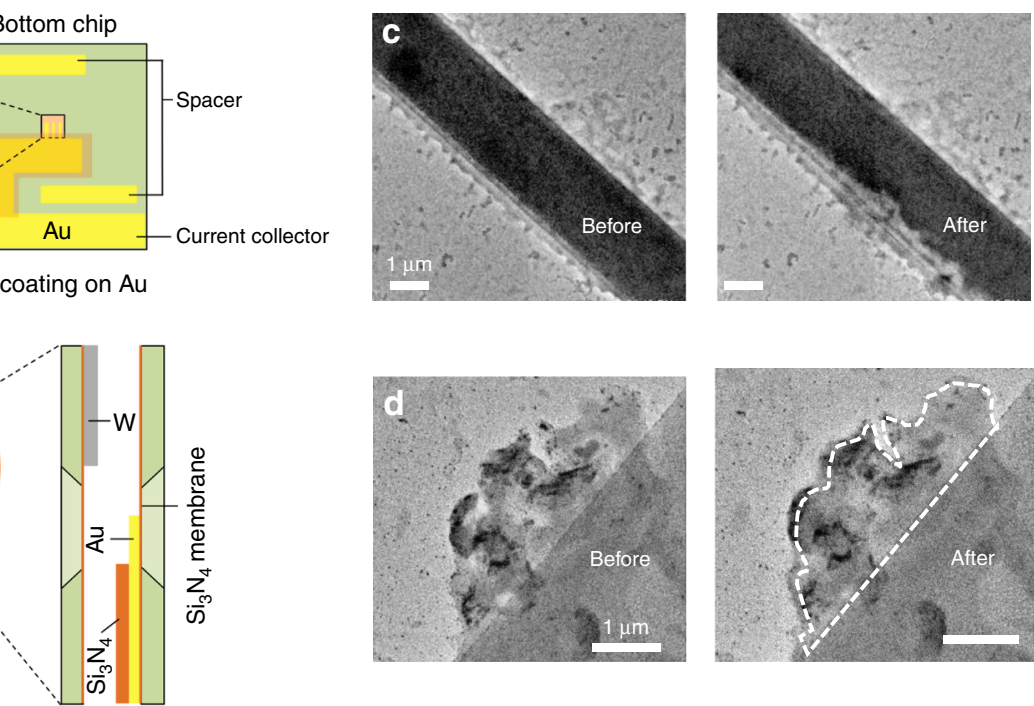
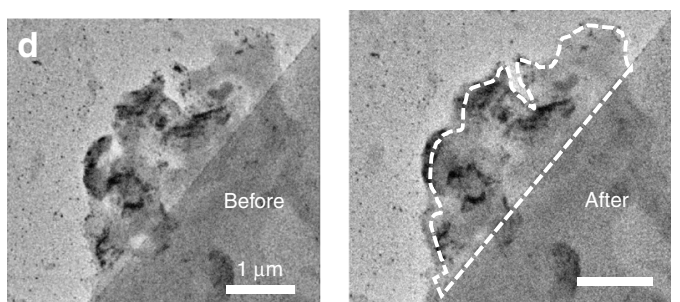

Fig. 4 In situ TEM investigation of the redox-active metallopolymer under electrochemical modulation. a Schematic illustration of the top and bottom chips for the liquid cell. The optical micrograph image shows the PVF film deposited on the Au electrode patterned on the $\mathrm{Si}_{3} \mathrm{~N}_{4}$ membrane window. $\mathbf{b}$ Chip assembly process. The two chips were overlapped and the two sides of the perimeter sealed with epoxy glue. The electrolyte was contacted with the side opening and injected into the cell via the capillary effect. A magnified cross-sectional view at the windows is illustrated. Detailed fabrication procedures for each component are given elsewhere ${ }^{34}$, with the polymer electrodeposition process described in Methods. c In situ TEM micrograph of PVF layer on top of gold chip. A solution of $20 \mathrm{mM} \mathrm{NaClO}_{4}$ was introduced and a CV @ $0.1 \mathrm{~V} / \mathrm{s}$ was applied to the two-electrode system; a clear expansion of the PVF film can be seen following ion insertion (Supplementary Movie 1). $\mathbf{d}$ Swelling and contrast change of a PVF film under electrochemical modulation in the presence of $10 \mathrm{mM}\left(\mathrm{NH}_{4}\right)_{2} \mathrm{Cr}_{2} \mathrm{O}_{7}$ (Supplementary Movie 3). See SI for all associated movies and cyclic voltammograms for Fig. 1c, d 
the understanding of adsorption mechanisms and future materials design. During electrochemical oxidation of the electrode materials, ion and solvent transfer can cause local swelling of the polymers, and affect electrochemical and chemical properties ${ }^{36,37}$. Indeed, studies of the behavior of thin-film Fc polymers under voltage and current response have played a central role in heterogeneous electrochemistry, as they provide a model system for fast electron transfer ${ }^{38-40}$ and dynamics of solvation ${ }^{41-43}$. PVF was electrodeposited from chloroform onto gold microelectrodes to form a thin uniform film (see Methods, Supplementary Information on microchip fabrication, and Supplementary Figures 1-6 for more details). Initially, $20 \mathrm{mM} \mathrm{NaClO}_{4}$ was introduced into the liquid cell as a model electrolyte for simulating brackish conditions. CV at a $0.01 \mathrm{~V} / \mathrm{s}$ scan rate of up to $2 \mathrm{~V}$ revealed a sharp expansion of the polymer film once the oxidation potential of the Fc units was attained (Fig. 4c, with associated LSV in Supplementary Figure 7), with a 30\% increase in thickness (see full kinetics of adsorption in Supplementary Movie 1). This expansion was attributed to the ingression of the counter anions together with their associated waters of solvation as $\mathrm{Fc} \rightarrow \mathrm{Fc}^{+}$, a phenomenon that has been inferred through indirect spectroscopic measurements ${ }^{36}$, but which is observed directly here through in situ microscopic imaging under TEM.

Desorption occurs on a much slower time-scale due to electron transfer and ion-pair dissociation kinetics during ion release and diffusional restructuring of the interfacial film as the ferrocenium $\left(\mathrm{Fc}^{+}\right)$reverts to $\mathrm{Fc}$. Unlike purely organic polymers, metallopolymers were found to provide sufficient contrast for direct electron imaging due to the presence of the metal centers. Reversible ion uptake and desorption were clearly observed with dichromate $\left(10 \mathrm{mM} \mathrm{NH}_{4} \mathrm{Cr}_{2} \mathrm{O}_{7}\right)$ as well. Due to the higher contrast of the heavier $\mathrm{Cr}$ ion (Fig. 4d, Supplementary Movies 2-4), an upconcentration of the anion within the film could be seen upon application of an oxidative potential. Chromium binding was observed in a series of movies taken at different locations on the coated electrode (SI movies 1-3), indicating the fast kinetics of film swelling $(<5 \mathrm{~s})$. In the case of chromium, there is a shift in the oxidation potential of the PVF film towards lower potentials relative to those observed with the perchlorate anion, indicating the strong binding affinity of ferrocenium for chromate anions (Supplementary Figure 7). Finally, no second-phase particle growth was observed in the TEM measurements under the voltage ranges tested, indicating that molecular binding plays a major role, and that phase transformation processes are not significant under these conditions.

\section{Discussion}

In summary, we have successfully investigated the anion-selective properties of the redox metallopolymer $\mathrm{Fc}$ for the removal of chromium and arsenic HMOAs from water under realistic operating conditions. PVF-CNT electrodes were used for the selective adsorption of two of the most prevalent and toxic HMOAs, with a high adsorption capacity $(>100 \mathrm{mg} / \mathrm{g}$ at saturation) and remarkable regeneration properties. For chromium, a coupling of the release and regeneration of the electrodes results in transformation of the hexavalent pollutant into the less harmful trivalent form. From a practical perspective, this two-step electroswing process allows for the purification of a water stream under dilute pollutant concentrations while simultaneously reducing the byproduct toxicity. In addition, the system presents fast kinetics, and is an order of magnitude more active compared to various ion-exchange beds or even non-redox electrochemical systems, making it suitable for household and remote-site water purification, environmental remediation, and high-throughput industrial operations. In situ TEM measurements with an electrochemical liquid cell provided direct evidence of the redoxdriven anion insertion into the poly(vinyl)ferrocenium film under charge, and the high affinity of the films for dichromate anions. Our work highlights the power of redox-mediated/Faradaic systems for the selective environmental capture and remediation of HMOAs, by showing strong binding selectivity and the possible coupling to an electron transfer process that mitigates the toxicity of the adsorbed element. In addition, the counter electrode reactions were found to be highly synergistic with the environmental transformation occurring at the metallopolymer electrode, pointing to the important role that electrochemical engineering can play in enabling an efficient reactive separation process. We also envision the use of these platforms for the recovery and valorization of waste streams in various chemical and electronic industries for a wider range of transition metal compounds.

\section{Methods}

PVF-CNT electrodes for electrochemical separation. The PVF-CNT electrodes were prepared following a drop-casting procedure ${ }^{23,26}$. A stock solution A of $80 \mathrm{mg}$ PVF (Polysciences Inc.) and $40 \mathrm{mg}$ multiwalled CNT (Sigma) was dissolved in $10 \mathrm{~mL}$ anhydrous chloroform, and a stock solution B of $40 \mathrm{mg}$ of CNT in $10 \mathrm{~mL}$ chloroform was also prepared. The two stock solutions were sonicated for $2 \mathrm{~h}$ in icy water, and stocks $A$ and $B$ were mixed in a 1:1 ratio. Electrodes were drop cast using $50 \mu \mathrm{L}$ of solution, and left to dry at $25^{\circ} \mathrm{C}$. For all systems, unless otherwise stated, the immersed electrochemical area was equivalent to $1 \mathrm{~cm}^{2}(1 \mathrm{~cm}$ by $1 \mathrm{~cm})$ with $2 \mathrm{mg}$ of PVF per electrode.

Electrochemical adsorption. The electrochemical separations were carried out on a BASi cell in a three-electrode configuration with an aqueous $\mathrm{Ag} / \mathrm{AgCl}$ reference electrode, and a Pt counter electrode, under ambient conditions. For adsorption and desorption tests, $5 \mathrm{~mL}$ of solution was used for the isotherm and equilibrium data measurements, and $8 \mathrm{~mL}$ for the kinetics tests. A background electrolyte concentration of $20 \mathrm{mM}$ of either $\mathrm{NaClO}_{4}$ or $\mathrm{NaCl}$ was used. To quantify kinetics, $0.1 \mathrm{~mL}$ aliquots were taken at variable time points for ICP assay. All electrochemical studies were performed on a VersaSTAT 4 potentiostat (Princeton Applied Research) with automatic IR compensation between $5 \Omega$ and $50 \mathrm{M} \Omega$. The uptake values are reported as the adsorption capacity normalized by the mass of the polymer ( $2 \mathrm{mg}$ of PVF per electrode, unless otherwise stated). For consistency, chronoamperometry was used for all the separation tests in this work, with chronopotentiometric measurements yielding comparable results.

In situ TEM microchip. In situ TEM observation of the chromate adsorption/ desorption on PVF-CNT film was performed on a liquid confining cell. The details of the cell dimensions and the fabrication procedure are provided elsewhere ${ }^{34}$. The liquid cell consisted of two separate chips with $\mathrm{Si}_{3} \mathrm{~N}_{4}$ membrane windows $(\sim 70 \mathrm{~nm}$ thick). The top chip had a tungsten electrode (counter electrode) and the bottom chip a gold electrode (working electrode). The gold electrode was coated with $\mathrm{Si}_{3} \mathrm{~N}_{4}$ except for the area on the membrane window to prevent the electrochemical reaction outside the field of view. The cells/microchips were then held by a minialligator clip at the gold current collector, and immersed into a $1 \mathrm{mg} / \mathrm{mL} \mathrm{PVF}$ solution in chloroform, with $100 \mathrm{mM}$ tetrabutylammonium hexafluorophosphate $\left(\mathrm{TBAPF}_{6}{ }^{-}\right)$. Electrodeposition was achieved by the application of a $+0.8 \mathrm{~V}$ vs. Ag/ $\mathrm{AgCl}$ potential to the microchip for $5 \mathrm{~min}$ to achieve optimal coating. The coating was observed under a high-resolution optical microscope. The optimization of the process under different electrochemical conditions, electrolyte chemistries, and concentrations is given in the Supplementary Information (Supplementary Figures 1-6). Once the polymer film was deposited on the assembled chip, we injected the electrolyte and completely sealed the cell. The cell was mounted on a Nanofactory Scanning Tunneling Microscope-TEM holder. Autolab PGSTAT101 was connected to the holder to perform the electrochemical tests. We used JEOL 2010F (operated at $200 \mathrm{kV}$ acceleration voltage) for the in situ TEM imaging. The configuration of the liquid cell chips and the assembly procedure are illustrated in Fig. 4a.

Liquid-phase analysis. Inductively-coupled plasma optical emission spectroscopy a PerkinElmer Optima 8000 ICP-OES spectrometer was used to quantify the concentrations of chromium and arsenic in solution. To establish a baseline for the ICP readings, a $2 \% \mathrm{w} / \mathrm{w} \mathrm{HNO}_{3}$ solution was prepared from $70 \% \mathrm{HNO}_{3}$ (SigmaAldrich, ACS reagent), and used as the solution into which the adsorbed species were electrochemically discharged, as well as to dilute any concentrated samples. Calibration solutions were made by diluting the ICP calibration standards (1000 \pm $2 \mathrm{mg} / \mathrm{L}, 2 \% \mathrm{w} / \mathrm{w} \mathrm{HNO}_{3}$ ) from Fluka Analytical, TraceCERT ${ }^{\oplus}$ prepared 2\% w/w $\mathrm{HNO}_{3}$ solution. A total of four calibration samples were prepared for each of the three cations examined, at concentrations of $10,1,0.5$, and $0.1 \mathrm{mg} / \mathrm{L}$ (with $2 \% \mathrm{w} / \mathrm{w}$ $\mathrm{HNO}_{3}$ being $0 \mathrm{mg} / \mathrm{L}$ ). After calibration, the linear fit was visually inspected, and the instrument was also set to perform a quality control check by resampling the 
$10 \mathrm{mg} / \mathrm{L}$ calibration solution to ascertain its calibrated concentration measurement. Each solution sample was measured in triplicate by the spectrometer to yield an averaged reading.

Spectrophotometric analysis of $\mathrm{Cr}$ oxidation state. To measure the content of $\mathrm{Cr}(\mathrm{VI})$ in the aqueous samples, a one-step colorimetric assay was used (BioAssay Systems QuantiChrom Chromium Assay Kit, DCRM-250). The method relies on a mix-incubate-measure protocol, and the samples of the solution were pre-diluted to fit within the $0.02-2 \mathrm{mg} / \mathrm{L}$ range for the assay. Whereas the amount of $\mathrm{Cr}(\mathrm{VI})$ was directly measured, the amount of $\mathrm{Cr}(\mathrm{III})$ was estimated by the difference in the total amount of $\mathrm{Cr}$ from ICP relative to that of $\mathrm{Cr}(\mathrm{VI})$, and also confirmed by an acid treatment to convert all the $\mathrm{Cr}(\mathrm{VI})$ to $\mathrm{Cr}(\mathrm{III})$.

Electronic structure calculations. We performed DFT calculations based on a generalized gradient approximation (GGA-PBE form) treatment of the exchange correlation method, implemented in the Vienna ab initio simulation package $(\text { VASP })^{44,45}$. The projector augmented-wave and plane-wave methods were used to describe core and valence electrons, respectively. The cutoff energy was set to be $400 \mathrm{eV}$, and in order to include the van der Waals interactions between moieties, we adopt Grimme's DFT-D3 scheme ${ }^{46}$. Since the gas-phase calculations greatly overestimate the interaction between molecules, we applied an implicit water solvation model that describes the electrostatics, cavitation, and dispersion effects 47,48 . In order to obtain the ground state, we used multiple different geometric configurations as initial structures for each system, and then optimized them without any symmetry constraints. The binding energy is defined as $\mathrm{BE}=E_{\mathrm{A}}^{-12-}+E_{\mathrm{Fc}}{ }^{+}$ $E_{\mathrm{AFc}}{ }^{0 /-}$, where $E$ refers to the total energy of the studied moiety. According to our calculations, the overall interaction trend in the gas phase and with solvation was the same, and as such, we base our discussions solely on the more physically relevant interactions with water solvation. In order to account for the entropy contribution to the binding between the ferrocenium and anionic moieties, we calculated their Helmholtz free energy at room temperature $(300 \mathrm{~K})$ with the solvation effect included. Following careful optimization of the structures with the convergence criteria of $1 \times 10^{-7} \mathrm{eV}$ and $1 \times 10^{-5} \mathrm{eV} / \AA$ for the total energy and force components, respectively, the vibrational frequencies were calculated through perturbation of each atom in all three directions. The Helmholtz free energy can be written as:

$$
F(T)=E(0)+\frac{1}{2} \sum_{s} \hbar \omega_{s}+k_{\mathrm{B}} T \sum_{s} \ln \left[1-\exp \left(-\hbar \omega_{s} / k_{\mathrm{B}} T\right)\right],
$$

where the first term, $E(0)$, represents the static energy at $0 \mathrm{~K}$. The second and third terms correspond to the zero-point energy and vibrational energy at finite temperatures, respectively. The $\omega_{s}$ refers to the sth vibrational frequency. The room temperature binding energy $\mathrm{BE}(T)$, accounting for vibrational entropy, was then evaluated by a simple difference: $\mathrm{BE}(T)=F_{\mathrm{Fc}+}(T)+F_{\text {anion }}(T)-F_{\mathrm{Fc} \text { anion }}(T)$. Variations in the temperature-dependent electron occupation and electron-phonon coupling were neglected. All these calculations were performed in VASP code.

\section{Data availability}

All relevant data are contained within the article, Supplementary Information and available from the authors upon reasonable request. The movies are uploaded as Supplementary Information to the paper, and have been compressed for reduced file size and ease visualization. Original files can be requested from the authors at x2su@mit.edu and kushima@mit.edu.

Received: 1 July 2018 Accepted: 18 October 2018

Published online: 08 November 2018

\section{References}

1. Elimelech, M. \& Phillip, W. A. The future of seawater desalination: energy, technology, and the environment. Science 333, 712-717 (2011).

2. Sharma, P. et al. Groundwater contaminated with hexavalent chromium [Cr (VI)]: a health survey and clinical examination of community inhabitants (Kanpur, India). PLoS ONE 7, e47877 (2012).

3. Nakano, Y., Takeshita, K. \& Tsutsumi, T. Adsorption mechanism of hexavalent chromium by redox within condensed-tannin gel. Water Res. 35, 496-500 (2001).

4. Rana-Madaria, P., Nagarajan, M., Rajagopal, C. \& Garg, B. S. Removal of chromium from aqueous solutions by treatment with carbon aerogel electrodes using response surface methodology. Ind. Eng. Chem. Res. 44, 6549-6559 (2005).

5. National Research Council. Alternatives for Ground Water Cleanup (National Acadmies of Sciences, Washington, 1994).
6. Patterson, R. R., Fendorf, S. \& Fendorf, M. Reduction of hexavalent chromium by amorphous iron sulfide. Environ. Sci. Technol. 31, 2039-2044 (1997).

7. Kikuchi, M., Syudo, A., Hukumori, M., Naito, C. \& Sawai, J. Changes in aquatic toxicity of potassium dichromate as a function of water quality parameters. Chemosphere 170, 113-117 (2017).

8. Jarup, L. Hazards of heavy metal contamination. Br. Med. Bull. 68, 167-182 (2003).

9. Mandal, B. K. \& Suzuki, K. T. Arsenic round the world: a review. Talanta $\mathbf{5 8}$, 201-235 (2002).

10. Dixit, S. \& Hering, J. G. Comparison of $\operatorname{arsenic}(\mathrm{V})$ and $\operatorname{arsenic}(\mathrm{III})$ sorption onto iron oxide minerals: implications for arsenic mobility. Environ. Sci. Technol. 37, 4182-4189 (2003).

11. Huang, G. L., Zhang, H. Y., Shi, J. X. \& Langrish, T. A. G. Adsorption of chromium(VI) from aqueous solutions using cross-linked magnetic chitosan beads. Ind. Eng. Chem. Res. 48, 2646-2651 (2009).

12. Recillas, S. et al. Chromium VI adsorption on cerium oxide nanoparticles and morphology changes during the process. J. Hazard. Mater. 184, 425-431 (2010).

13. Santhosh, C. et al. Magnetic $\mathrm{SiO}_{2} @ \mathrm{CoFe}_{2} \mathrm{O}_{4}$ nanoparticles decorated on graphene oxide as efficient adsorbents for the removal of anionic pollutants from water. Chem. Eng. J. 322, 472-487 (2017).

14. Rengaraj, S., Yeon, K.-H. \& Moon, S.-H. Removal of chromium from water and wastewater by ion exchange resins. J. Hazard. Mater. 87, 273-287 (2001).

15. Alsbaiee, A. et al. Rapid removal of organic micropollutants from water by a porous beta-cyclodextrin polymer. Nature 529, 190-U146 (2016).

16. Ahualli, S., Iglesias, G. R., Fernandez, M. M., Jimenez, M. L. \& Delgado, A. V Use of soft electrodes in capacitive deionization of solutions. Environ. Sci. Technol. 51, 5326-5333 (2017).

17. Kim, T., Gorski, C. A. \& Logan, B. E. Low energy desalination using battery electrode deionization. Environ. Sci. Technol. Lett. 4, 444-449 (2017).

18. Lee, J., Kim, S., Kim, C. \& Yoon, J. Hybrid capacitive deionization to enhance the desalination performance of capacitive techniques. Energy Environ. Sci. 7, 3683-3689 (2014)

19. Zhao, R., Biesheuvel, P. M. \& van der Wal, A. Energy consumption and constant current operation in membrane capacitive deionization. Energy Environ. Sci. 5, 9520-9527 (2012).

20. Su, X. \& Hatton, T. A. Electrosorption at functional interfaces: from molecular-level interactions to electrochemical cell design. Phys. Chem. Chem. Phys. 19, 23570-23584 (2017).

21. Liu, Y. et al. Review on carbon-based composite materials for capacitive deionization. RSC Adv. 5, 15205-15225 (2015).

22. Suss, M. E. et al. Water desalination via capacitive deionization: what is it and what can we expect from it? Energy Environ. Sci. 8, 2296-2319 (2015).

23. Su, X., Kulik, H. J., Jamison, T. F. \& Hatton, T. A. Anion-selective redox electrodes: electrochemically mediated separation with heterogeneous organometallic interfaces. Adv. Funct. Mater. 26, 3394-3404 (2016).

24. Su, X. et al. Asymmetric Faradaic systems for selective electrochemical separations. Energy Environ. Sci. 10, 1272-1283 (2017).

25. Su, X. \& Hatton, T. A. Redox-electrodes for selective electrochemical separations. Adv. Colloid Interface Sci. 244, 6-20 (2017).

26. Mao, X., Rutledge, G. C. \& Hatton, T. A. Polyvinylferrocene for noncovalent dispersion and redox-controlled precipitation of carbon nanotubes in nonaqueous media. Langmuir 29, 9626-9634 (2013).

27. Hu, J., Chen, G. \& Lo, I. M. C. Removal and recovery of $\mathrm{Cr}(\mathrm{VI})$ from wastewater by maghemite nanoparticles. Water Res. 39, 4528-4536 (2005).

28. Farmer, J. C. et al. Electrosorption of chromium ions on carbon aerogel electrodes as a means of remediating ground water. Energy Fuels 11, 337-347 (1997).

29. Manning, B. A., Kiser, J. R., Kwon, H. \& Kanel, S. R. Spectroscopic investigation of $\mathrm{Cr}(\mathrm{III})$ - and $\mathrm{Cr}(\mathrm{VI})$-treated nanoscale zerovalent iron. Environ. Sci. Technol. 41, 586-592 (2007).

30. Fendorf, S. E. \& Li, G. C. Kinetics of chromate reduction by ferrous iron. Environ. Sci. Technol. 30, 1614-1617 (1996).

31. Frenzel, I., Holdik, H., Barmashenko, V., Stamatialis, D. F. \& Wessling, M. Electrochemical reduction of dilute chromate solutions on carbon felt electrodes. J. Appl. Electrochem. 36, 323-332 (2005).

32. Tang, W., Sanville, E. \& Henkelman, G. A grid-based Bader analysis algorithm without lattice bias. J. Phys. Condens. Matter 21, 084204 (2009).

33. Kushima, A. et al. Charging/discharging nanomorphology asymmetry and rate-dependent capacity degradation in Li-oxygen battery. Nano Lett. 15, $8260-8265$ (2015)

34. Kushima, A. et al. Liquid cell transmission electron microscopy observation of lithium metal growth and dissolution: root growth, dead lithium and lithium flotsams. Nano Energy 32, 271-279 (2017).

35. Niu, J. J. et al. In situ observation of random solid solution zone in $\mathrm{LiFePO} 4$ electrode. Nano Lett. 14, 4005-4010 (2014). 
36. Bruckenstein, S., Fensore, A. T. \& Hillman, A. R. Time-resolved mono-anion, di-anion, and solvent transfers into a poly(vinylferrocene)-modified electrode. J. Electrochem. Soc. 145, L24-L26 (1998).

37. Jureviciute, I., Bruckenstein, S. \& Hillman, A. R. Counter-ion specific effects on charge and solvent trapping in poly(vinylferrocene) films. J. Electroanal. Chem. 488, 73-81 (2000).

38. Nakahama, S. \& Murray, R. W. The effect of composition of a ferrocenecontaining redox polymer on the electrochemistry of its thin-film coatings on electrodes. J. Electroanal. Chem. 158, 303-322 (1983).

39. Carlin, C. M., Kepley, L. J. \& Bard, A. J. Polymer-films on electrodes. 16. In situ ellipsometric measurements of polybipyrazine, polyaniline and polyvinylferrocene films. J. Electrochem. Soc. 132, 353-359 (1985).

40. Bard, A. J. \& Faulkner, L. R. Electrochemical Methods: Fundamentals and Applications 2nd edn (Wiley, New York, 2000).

41. Glidle, A. et al. Use of neutron reflectivity to measure the dynamics of solvation and structural changes in polyvinylferrocene films during electrochemically controlled redox cycling. Langmuir 25, 4093-4103 (2009).

42. Mizunuma, M., Ohsaka, T., Miyamoto, H. \& Oyama, N. Investigation of ion and solvent transport accompanying redox reactions of polyvinylferrocene films using an in situ electrochemical quartz crystal microbalance technique. Bull. Chem. Soc. Jpn. 64, 2887-2893 (1991).

43. Pater, E. M., Bruckenstein, S. \& Hillman, A. R. Film mass and volume changes accompanying redox-driven solvent and salt transfer during redox switching of polyvinylferrocene films. J. Chem. Soc. Faraday Trans. 94, 1097-1103 (1998).

44. Kresse, G. \& Furthmuller, J. Efficient iterative schemes for ab initio totalenergy calculations using a plane-wave basis set. Phys. Rev. B 54, 11169-11186 (1996).

45. Kresse, G. \& Joubert, D. From ultrasoft pseudopotentials to the projector augmented-wave method. Phys. Rev. B 59, 1758-1775 (1999).

46. Grimme, S., Antony, J., Ehrlich, S. \& Krieg, H. A consistent and accurate $\mathrm{ab}$ initio parametrization of density functional dispersion correction (DFT-D) for the 94 elements H-Pu. J. Chem. Phys. 132, 154104 (2010).

47. Mathew, K., Sundararaman, R., Letchworth-Weaver, K., Arias, T. A. \& Hennig, R. G. Implicit solvation model for density-functional study of nanocrystal surfaces and reaction pathways. J. Chem. Phys. 140, 084106 (2014).

48. Fishman, M., Zhuang, H. L. L., Mathew, K., Dirschka, W. \& Hennig, R. G. Accuracy of exchange-correlation functionals and effect of solvation on the surface energy of copper. Phys. Rev. B 87, 245402 (2013).

\section{Acknowledgements}

We thank Elaine Lee and Liruonong Zhang for their help and assistance in preparing the electrodes, and Kai-Jher Tan for his assistance with the ICP measurements. We thank
David Allan Bloore for his help with molecular visualization of the DFT results. We also thank Dr. Arthur Pelton for the kind assistance in pointing us to the online FactSage Module for E-pH calculations. J.L. acknowledges support by NSF ECCS-1610806.

\section{Author contributions}

X.S. and T.A.H. conceived the concepts. T.A.H. and J.L. guided the project by providing scientific input and supervision. X.S. and A.K. carried out the materials synthesis and characterization, with A.K. performing the in situ electrochemical TEM imaging. X.S. and C.H. performed the electrochemical separation tests and liquid assays. J.Z. performed the electronic structure calculations and associated analysis. X.S. wrote the paper with input and revisions from all authors.

\section{Additional information}

Supplementary Information accompanies this paper at https://doi.org/10.1038/s41467018-07159-0.

Competing interests: The authors declare no competing interests.

Reprints and permission information is available online at http://npg.nature.com/ reprintsandpermissions/

Publisher's note: Springer Nature remains neutral with regard to jurisdictional claims in published maps and institutional affiliations.

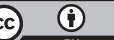

Open Access This article is licensed under a Creative Commons Attribution 4.0 International License, which permits use, sharing, adaptation, distribution and reproduction in any medium or format, as long as you give appropriate credit to the original author(s) and the source, provide a link to the Creative Commons license, and indicate if changes were made. The images or other third party material in this article are included in the article's Creative Commons license, unless indicated otherwise in a credit line to the material. If material is not included in the article's Creative Commons license and your intended use is not permitted by statutory regulation or exceeds the permitted use, you will need to obtain permission directly from the copyright holder. To view a copy of this license, visit http://creativecommons.org/ licenses/by/4.0/.

(C) The Author(s) 2018 